\title{
Adult Acute Monoblastic Leukemia
}

National Cancer Institute

\section{Source}

National Cancer Institute. Adult Acute Monoblastic Leukemia. NCI Thesaurus. Code C9156.

An acute monoblastic leukemia occurring in adults. 